\title{
Morphometric MRI Study of the Brain Ventricles in Healthy Turkish Subjects
}

\author{
Estudio Morfométrico de Resonancia Magnética de los \\ Ventrículos Cerebrales en Sujetos Turcos Sanos
}

Sema Polat ${ }^{1}$; Fatma Yasemin Öksüzler²; Mahmut Öksüzler ${ }^{3}$; Ayse Gül Kabakci ${ }^{1}$ \& Ahmet Hilmi Yücel ${ }^{1}$

POLAT, S.; ÖKSÜZLER, F. Y.; ÖKSÜZLER, M.; KABAKCI, A. G. \& YÜCEL, A. H. Morphometric MRI study of the brain ventricles in healthy Turkish subjects. Int. J. Morphol., 37(2):554-560, 2019.

SUMMARY: The aim of this study was to determine the normal values of brain ventricles and indices in healthy subjects in our population using magnetic resonance imaging (MRI) and to reveal sex and age related differences. The MRI of two hundred-sixty-five healthy individuals aged between eighteen and eighty-seven years were examined and the midsagittal and axial images were used for measurements. The measurements were performed from MRI on a Workstation. The following mean values of brain ventricles and indices were observed; frontal horn width (FHW) (33.14 mm); third (3rd) ventricle width (TVW) (3.37 mm); fourth ventricle anteroposterior width (FVWAP) $(9.93 \mathrm{~mm})$; fourth ventricle transverse width (FVWT) $(12.40 \mathrm{~mm})$; and the maximum transverse inner diameter of the skull (TIDS) (128.75 mm) in females. The same dimensions were $34.85 \mathrm{~mm}, 3.91 \mathrm{~mm}, 10.26 \mathrm{~mm}, 12.81 \mathrm{~mm}$, and $134.68 \mathrm{~mm}$ in males, respectively. There were statistically significantly differences in the frontal horn width, third (3rd) ventricle width, and the maximum transverse inner diameter of the skull values in between sexes. The mean values of Evans' index which obtanied with maximum width between the frontal horns of the lateral ventricles divided by the maximum transverse inner diameter of the skull were found as 0.280 \pm 0.172 in females; whereas the same dimensions were calculated $0.276 \pm 0.161$ in males. These values were lower in healthy male subjects than females, however; there were no found significantly difference between groups. Present findings obtained from MRI are necessary anatomical baseline data for interpreting pathological changes, planning surgery, and determining presence and progress of some neurological diseases.

KEY WORDS: Brain ventricles; Morphometric study; MRI.

\section{INTRODUCTION}

The brain ventricular system which is cavity is filled with cerebrospinal fluid (Honnegowda et al., 2017). In diencephalon of the forebrain the third ventricle (TV) is located between the right and left thalamus; whereas, the fourth ventricle (FV) which is a large tent-shaped is settled between cerebellum and brainstem. Moreover, it corresponds to at the back of the pons and top half part of the medulla oblangata in the hindbrain (Mavridis, 2014; Gameraddin et al., 2015). The FV linked with the third ventricle via cerebral aqueduct (aqueduct of Sylvius), and caudally via the median aperture (foramen of Magendie) with vallecula cerebelli and cisterna magna with the spinal canal and laterally, via the lateral aperture (foramina of Luschka) with the cerebellopontine angles (Mavridis). There are many pathological conditions of the fourth ventricle foramina. Those are maybe congenital or acquired. Because, they have relations with many crucial structures of the mesencephalon, pons, medulla oblangata and cerebellum. That causes hydrocephalus by the reason of the cerebrospinal fluid flow obstruction. Furthermore, this structure are anatomically and neurosurgically sensitive and significant part of the brain ventricular system (Mavridis). Ventricular size measurement is necessary for determination and follow-up many neurological illness, and pathologies. Ventricular enlargement is an indicator of brain parenchyma loss (Karakas et al, 2011). Furthermore, ventricular size measurements are used in studies hydrocephalus, schizophrenia, tumors, trauma, Alzheimer's disease, Parkinson's disease, gender, aging, and athropy which is

\footnotetext{
${ }^{1}$ Cukurova University, Faculty of Medicine, Department of Anatomy. Balcali-Sarıçam/Adana, Turkey.

${ }^{2}$ Adana City Hospital, Department of Radiology, Adana, Turkey.

${ }^{3}$ Adana Medline Hospital, Department of Radiology,Adana, Turkey.
} 
associated with many neurological diseases such as stroke and dementia, Huntington's disease (Karakas et al.; Gameraddin et al.; Honnegowda et al.) and provides useful indices of cerebral asymmetry and atrophy. The knowledge of ventricular system anatomy is essential for clinicians, neurosurgeons and radiologists (Kanakaraj et al., 2016; Farheen \& Sukre, 2017). Due to literature findings, the ventricular size is considered as a potential indicator in determination of many diseases related with brain. Additionally, the normal reference values of ventricles obtained MRI are necessary to form the baseline data for interpreting pathological changes, planning surgery, and determining presence and progress of some neurological diseases.

The purpose of this study was to document the morphometric and anatomic measurements of ventricles and indices, and to identify sex and age related differences of our populations. So, these normal values of healthy.

\section{MATERIAL AND METHOD}

This study was carried out from the two hundredsixty five healthy subjects (one hundred fifty-five females and one hundred-ten males) aged between eighteen and eighty-seven years over a period of three years between January 2015 and January 2018. However, the width of third and fourth venticles, and anteroposterior width of one hundred-eighty four healthy subjects, whereas the frontal horn width and brain transverse diameter of two hundred sixty five were measured.

All the test procedures were approved by ethics committee. The study is based on retrospective evaluation of Cerebral MRI. Cerebral MRI findings were evaluated by three observers [two radiologists (FYÖ and MÖ) and observer 2, an anatomist (SP)]. The subjects were selected by criteria of optimal health. Moreover, inclusion criteria for subjects were no history of oncologic illness, no hemiplegia, no intracranial lesions, no neurological signs, current or past psychiatric illness or alcoholism or drug use. MRI was performed using a 1.5 T MRI system (Siemens; Essenza, Erlangen, Germany). Brain MRI protocol including axial T2-weighted turbo spin echo (TR:3600, TE: $87 \mathrm{~ms}$; slice thickness $5 \mathrm{~mm}$; gap $1.5 \mathrm{~mm}$ ) was used. The measurements were performed from digital MRI images on a hospital using caliper function with $\mathrm{x} 2$ magnification. Using the midsagittal T2weighted spin echo image, the following parameters of brain regions and ventricular system were evaluated (Figs. 1, 2 and 3).

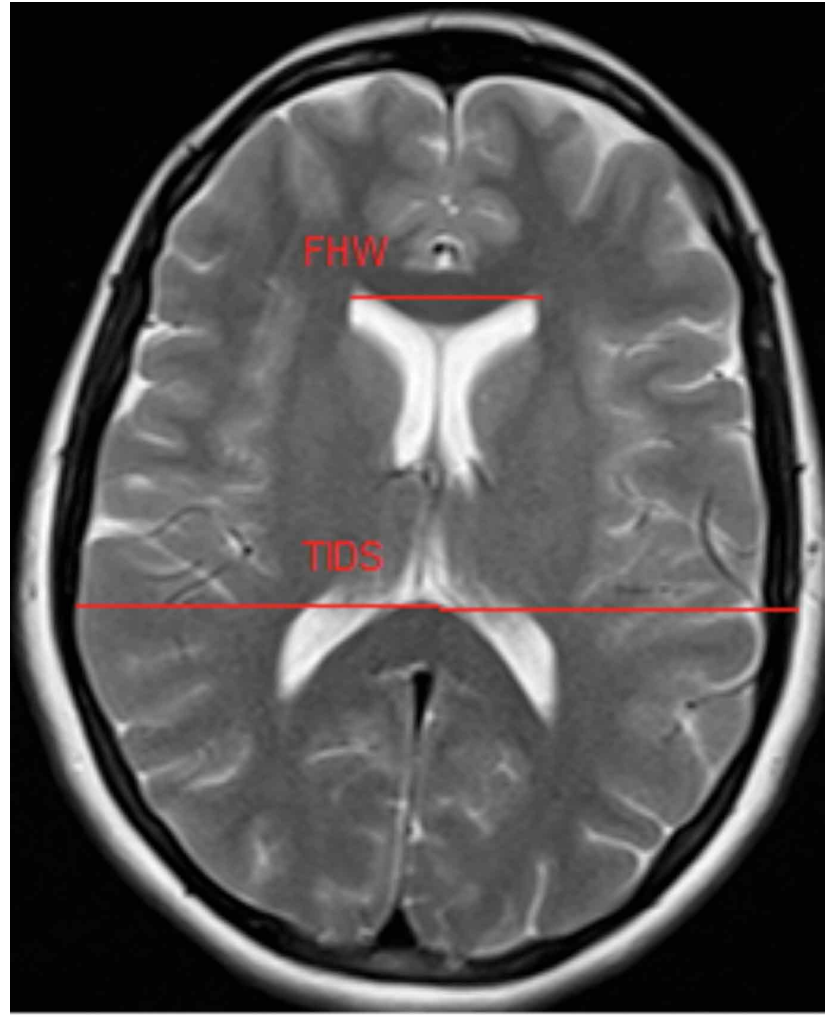

Fig. 1. Axial T2-weighted Turbo Spin Echo MRI (TR:3600, TE:87 $\mathrm{ms}$ ) of a measurement areas of healthy subjects. (FH) Frontal horn width. (TIDS) The maximum transverse inner diameter of the skull.

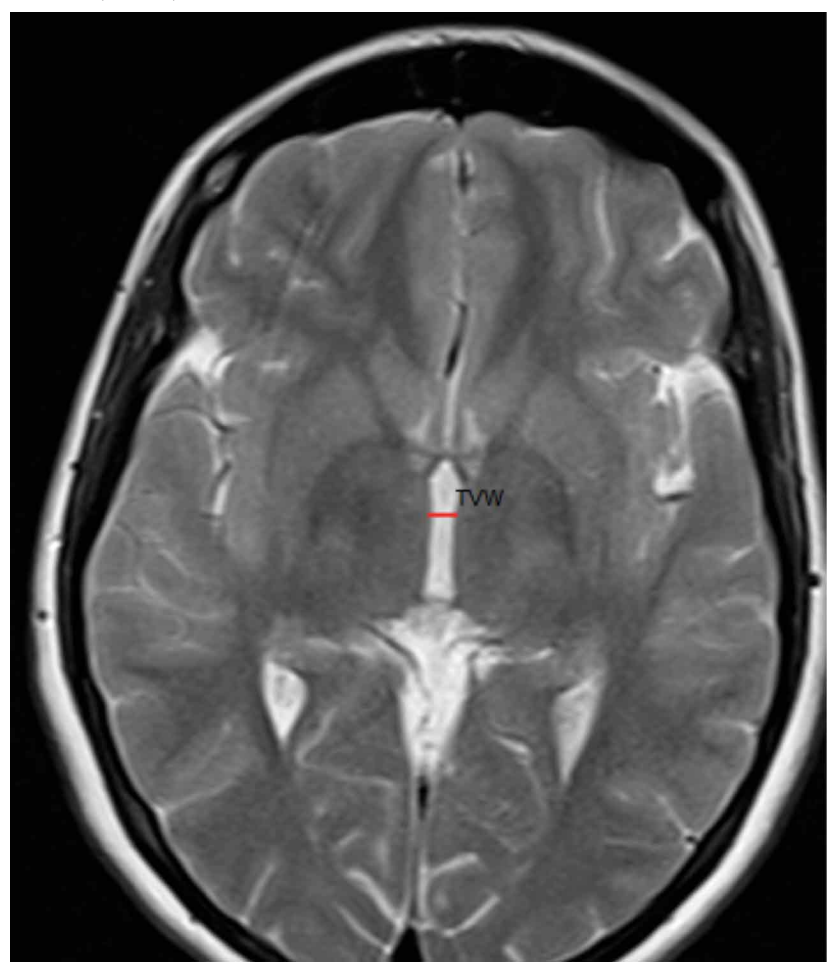

Fig. 2. Axial T2-weighted Turbo Spin Echo MRI (TR:3600, TE:87 $\mathrm{ms}$ ) of measurement areas of healthy subjects. (TVW) The width of the third (3rd) ventricle. (FVWAP). 


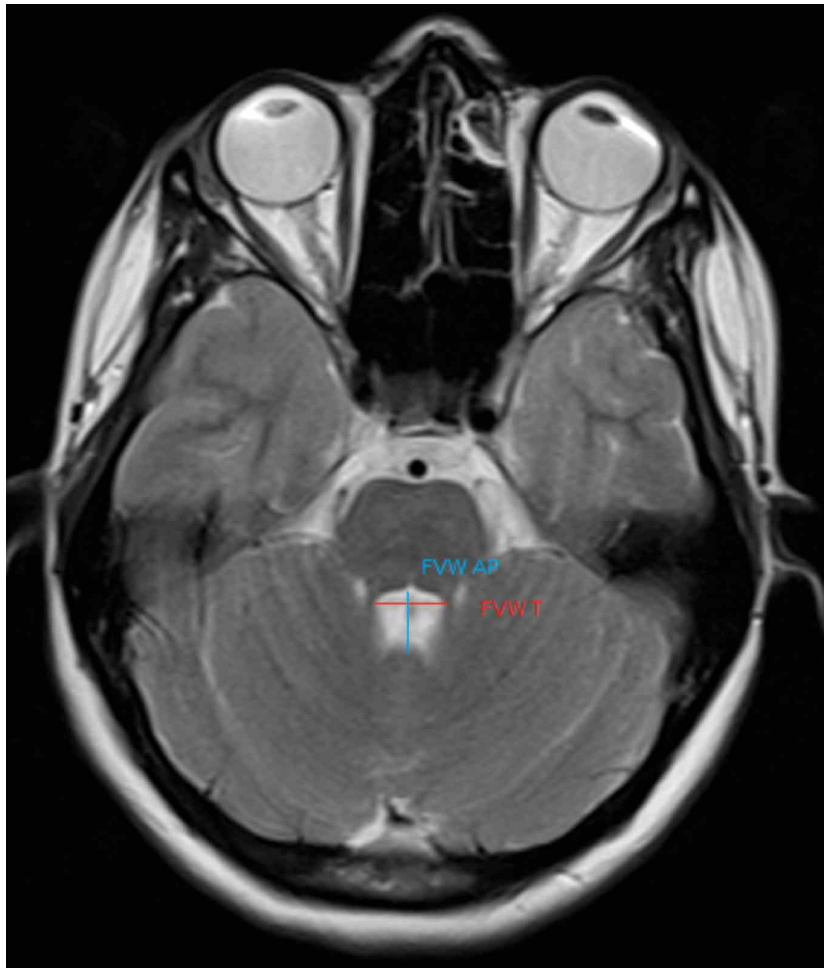

Fig. 3. Axial T2-weighted Turbo Spin Echo MRI (TR:3600, TE:87 $\mathrm{ms}$ ) of measurement areas of healthy subjects. (FVWAP) The anteroposterior width of the fourth (4th) ventricle. (FVWT) The transverse width of the fourth (4th) ventricle. (PTD)

(TVW) The width of the third $\left(3^{\text {rd }}\right)$ ventricle (The maximum width of the third ventricle) (FVWAP) The anteroposterior width of the fourth $\left(4^{\text {th }}\right)$ ventricle (The maximum width of the fourth ventricle from anteroposterior). (FVWT) The transverse width of the fourth $\left(4^{\text {th }}\right)$ ventricle (The maximum transverse width of the fourth ventricle).

Two measurements were determined using T2weighted Turbo spin echo MRI. The measurements were as follows.
( FHW ) Frontal horn width (The maximum between frontal horns of the lateral ventricles).

( TIDS) The maximum transverse inner diameter of the skull at the same level

After these measurements, Evans' ratio was calculated. This index were determined that maximum width between the frontal horns of the lateral ventricles divided by the maximum transverse inner diameter of the skull. Estimations were expressed as millimeters. The SPSS 21.0 program was used for statistical analysis of the measurement results. From these measurements, means, standard deviations (SD), minimum and maximum values were calculated; $p<0.001, p<0.01$ and $p<0.05$ were considered statistically significant.

\section{RESULTS}

The ages of two hundred sixty five healthy individuals (one hudred fifty five females and one hundred ten males) were 18-87 years over a period of 3 years between January 2015 and January 2018. However, the width of third and fourth venticles, pons transverse and anteroposterior width of one hundred eighty four healthy subjects; whereas, the frontal horn width and brain transverse diameter of two hundred sixty five subjects were measured.

MRI results of brain ventricular size $(\mathrm{mm})$ and indices in healthy subjects were shown in Tables I and II. From the 265 MRI images, frontal horn width, the maximum transverse inner diameter of the skull and Evans index were measured (Fig. 1). Moreover, from 184 MRI images, the width of the third $\left(3^{\text {rd }}\right)$ ventricle, the anteroposterior width of the fourth $\left(4^{\text {th }}\right)$ ventricle and the transverse width of the fourth $\left(4^{\text {th }}\right)$ ventricle were calculated (Figs. 2 and 3). The mean scores of the width of the third $\left(3^{\text {rd }}\right)$ ventricle (TVW), the anteroposterior width of the

Table I. MRI results of brain ventricular size $(\mathrm{mm})$ and indices in healthy subjects.

\begin{tabular}{llllll}
\hline Measurements & $\mathrm{N}$ & Sex & Mean & SD & P \\
\hline Frontal horn width (FHW) & 155 & Female & 33.14 & 3.06 & $<0.001$ \\
& 110 & Male & 34.85 & 3.41 & $=0.002$ \\
Third ventricle width (TVW) & 110 & Female & 3.37 & 1.03 & 1.24 \\
& 74 & Male & 3.91 & 1.66 & 0.185 \\
Fourth ventricle antero-postero width (FVWAP) & 110 & Female & 9.93 & 1.65 & \\
& 74 & Male & 10.26 & 1.65 & 0.201 \\
Fourth ventricle transverse width (FVWT) & 110 & Female & 12.40 & 2.04 \\
& 74 & Male & 12.81 & 2.17 & \\
The maximum inner transverse diameter of the skull (TIDS) & 155 & Female & 128.75 & 17.96 & $=0.006$ \\
& 110 & Male & 134.68 & 16.39 & \\
Evans index (EI) & 155 & Female & 0.280 & 0.172 & 0.862 \\
& 110 & Male & 0.276 & 0.161 & \\
\hline
\end{tabular}


fourth $\left(4^{\text {th }}\right)$ ventricle (FVWAP), the transverse width of the fourth $\left(4^{\text {th }}\right)$ ventricle (FVWT), frontal horn width (FHW) and, the maximum transverse inner diameter of the skull at the same level (TIDS) were higher in healthy male subjects than in healthy female subjects, whereas the Evans ratio (FH/TIDS) were lower in healthy males than in females. According to these results, there were statistically significantly differences in the frontal horn width, third $\left(3^{\text {rd }}\right)$ ventricle width, and the maximum transverse inner diameter of the skull values in between two groups. Addtionally, the mean values of Evans'index were found as $0.280 \pm 0.172$ in females; whereas the same dimensions were calculated $0.276 \pm 0.161$ in males. These values were lower in healthy male subjects than females (Table I). However, there were no statistically difference between genders $(\mathrm{p}>0.05)$. Furthermore, the study group divided six groups according to age as $18-30$ years, first group; $31-40$ years, second group; 41-50 years, third group; 51-60 years, fourth group; 61-70 years, fifth group; and 71-87 years sixth group. Moreover, while there were statistically difference in the frontal horn width, third ventricle width and fourth ventricle transverse width between six groups. The EI value was the lowest in fourth group aged betwen 61 and 70 years.

Table II. MRI results of brain ventricular size $(\mathrm{mm})$ and indices in healthy subjects according to ages.

\begin{tabular}{|c|c|c|c|c|c|c|}
\hline Measurements & Group I & Group II & Group III & Group IV & Group V & Group VI \\
\hline FHW & $\mathrm{N}=53$ & $\mathrm{~N}=77$ & $\mathrm{~N}=31$ & $\mathrm{~N}=26$ & $\mathrm{~N}=52$ & $\mathrm{~N}=26$ \\
\hline & $32.84 \pm 2.55$ & $33.47 \pm 3.14$ & $33.83 \pm 3.42$ & $32.94 \pm 2.99$ & $35.37 \pm 3.85$ & $34.94 \pm 3.09$ \\
\hline $\begin{array}{l}\text { Significance value } \\
\text { between groups (p) }\end{array}$ & \multicolumn{6}{|c|}{$<0.001$} \\
\hline & $\mathrm{N}=53$ & $\mathrm{~N}=77$ & $\mathrm{~N}=31$ & $\mathrm{~N}=18$ & $\mathrm{~N}=5$ & - \\
\hline TVW & $3.29 \pm 0.80$ & $3.35 \pm 1.08$ & $4.10 \pm 1.19$ & $4.14 \pm 1.33$ & $5.40 \pm 1.33$ & - \\
\hline $\begin{array}{l}\text { Significance value } \\
\text { between groups }(p)\end{array}$ & \multicolumn{6}{|c|}{$<0.001$} \\
\hline FVW ${ }_{\text {AP }}$ & $\begin{array}{c}\mathrm{N}=53 \\
10.37 \pm 1.77\end{array}$ & $\begin{array}{c}\mathrm{N}=77 \\
10.12 \pm 1.59\end{array}$ & $\begin{array}{c}\mathrm{N}=31 \\
9.64 \pm 1.68\end{array}$ & $\begin{array}{c}\mathrm{N}=18 \\
9.67 \pm 1.59\end{array}$ & $\begin{array}{c}\mathrm{N}=5 \\
9.88 \pm 1.26\end{array}$ & $\begin{array}{l}- \\
-\end{array}$ \\
\hline $\begin{array}{l}\text { Significance value } \\
\text { between groups }(p)\end{array}$ & \multicolumn{6}{|c|}{0.299} \\
\hline & $\mathrm{N}=53$ & $\mathrm{~N}=77$ & $\mathrm{~N}=31$ & $\mathrm{~N}=18$ & $\mathrm{~N}=5$ & - \\
\hline $\mathrm{FVW}$ & $12.79 \pm 1.97$ & $12.22 \pm 1.95$ & $12.71 \pm 1.68$ & $12.31 \pm 2.00$ & $15.54 \pm 5.09$ & - \\
\hline $\begin{array}{l}\text { Significance value } \\
\text { between groups }(p)\end{array}$ & \multicolumn{6}{|c|}{0.009} \\
\hline & $\mathrm{N}=53$ & $\mathrm{~N}=77$ & $\mathrm{~N}=31$ & $\mathrm{~N}=26$ & $\mathrm{~N}=52$ & $\mathrm{~N}=26$ \\
\hline & $\begin{array}{c}129.79 \pm \\
21.58\end{array}$ & $\begin{array}{l}130.77 \pm \\
22.38\end{array}$ & $\begin{array}{c}134.19 \pm \\
21.22\end{array}$ & $\begin{array}{c}132.45 \pm \\
6.94\end{array}$ & $\begin{array}{c}130.73 \pm \\
6.90\end{array}$ & $\begin{array}{c}131.56 \pm \\
7.31\end{array}$ \\
\hline $\begin{array}{l}\text { Significance value } \\
\text { between groups }(\mathrm{p})\end{array}$ & \multicolumn{6}{|c|}{0.918} \\
\hline & $\mathrm{N}=53$ & $\mathrm{~N}=77$ & $\mathrm{~N}=31$ & $\mathrm{~N}=26$ & $\mathrm{~N}=52$ & $\mathrm{~N}=26$ \\
\hline EI & $0.29 \pm 0.21$ & $0.29 \pm 0.21$ & $0.29 \pm 0.23$ & $0.25 \pm 0.03$ & $0.27 \pm 0.03$ & $0.27 \pm 0.04$ \\
\hline $\begin{array}{l}\text { Significance value } \\
\text { between groups }(\mathrm{p})\end{array}$ & \multicolumn{6}{|c|}{0.908} \\
\hline
\end{tabular}

\section{DISCUSSION}

Magnetic resonance imaging (MRI), allows measurement of linear distances in involved image plane, by using software (Duffner et al., 2003). Cerebral ventricular system assess changes which are due to growth, ageing, and pathologies like intrinsic and extrinsic. The cerebral ventricular system consists of interconnected spaces and channels. It originates from the embryonic neural tube cen- tral lumen. It consists of lateral ventricle, third ventricle, and fourth ventricle. Third ventricle is a space that lies between the two halves of the diencephalon and it communicates with the lateral ventricles by foramina of monro. Also, it communicates with the fourth ventricle by the cerebral aqueduct (aqueduct of Sylvius). The fourth ventricle is a pyramid shaped space between the pons and 
medulla and cerebellum. Addtionally, inferiorly it turns into a narrow channel and continues into spinal cord as central canal (Kanakaraj et al.). There are cerebrospinal fluid in ventricular system, so it is a significant part of the brain. The knowledge of ventricular system anatomy is necessary for clinicians, neurosurgeons and radiologists (Farheen \& Sukre; Kanakaraj et al.). Ventricular enlargement defines loss in volume of brain parenchyma and this atrophy is associated with many neurological diseases like stroke and dementia (Kulkarni et al., 1999; Jamous et al., 2003; Aukland et al., 2008; Karakas et al.). It was also stated that the most apparent finding is enlargement in the lateral and third venticles of schizophrenic patients and an increase in ventricular size in proportion to progression of the disease in multiple sclerozis (Liu et al., 1999; Turner et al., 2001; Karakas et al.).

The frontal horn width was found as $35 \mathrm{~mm}$ and 33 $\mathrm{mm}$ in Norway males and females (Aukland et al.). In South Indians, the corresponding value were found as $34.1 \mathrm{~mm}$ and $31.8 \mathrm{~mm}$ in males and females respectively (Arun Kumar et al., 2017a). In Germany healthy population, this was 30.1 $\mathrm{mm}$, whereas the corresponding value was $35.6 \mathrm{~mm}$ in hydrocephalic patients (Duffner et al.). In this study, the same measurement was $33.14 \mathrm{~mm}$ and $34.85 \mathrm{~mm}$ in females and males. The inner transverse diameter of skull was reported as $12.51 \mathrm{~cm}$ and $12.06 \mathrm{~cm}$ in Indian males and females, respectively. This value increases as age increases (Arun Kumar et al., 2017b). In this paper, this value was 128.75 $\mathrm{mm}$ and 134.68 in females and males, respectively. TIDS value was higher in males than females as similarly to literature. Frontal horn width was 3.18 in females aged between 20-60 years, whereas in males the same measurement was 3.41 aged 20-60 years. Increased age the FHW increased in both females and males (Arun Kumar et al., 2017a).

The linear measurements of ventricles were made for evaluating the normative ventricles'values in this paper. Lateral ventricles enlargement was evaluated by averages of Evans ratio which is an important criteria. If this index is 0.3 or greater, it shows cut off value in diagnosis of hydrocephalus (Ng et al., 2009; Patnaik et al., 2016; Arun Kumar et al., 2017a). Normal reference data for Evans index should be 0.29 or less (Arun Kumar et al., 2017a and 2017b). Additionally, this value based on international guidelines. Evans index (EI) is also a valid estimated index in posttraumatic ventriculomegaly (Jehangir et al., 2018). EI is related with some conditions such as normal ageing, neurodegenarative diseases, tumors, trauma, and some hydrocephalus types, alcoholism, dementia, cerebral atrophy, multiple sclerosis. Also, this index is used to understand correlation with visual function in children with hydrocephalus and EI is used in follow-up ventriculoperitoneal shunt (Patnaik et al.; Arun Kumar et al., 2017a). In literature, due to increase in age and decrease in body mass index (BMI), there is decrease in the brain weight and rise in the ventricle size. But, brain atrophy maybe compensated by increase in the ventricle size, although the EI does not surpass 0.3 (Moore et al., 2012; Kanakaraj et al.; Arun Kumar et al., 2017a). We determined this index that maximum width between the frontal horns of the lateral ventricles divided by the maximum transverse inner diameter of the skull as noted in literature data (Karakas et al.; Moore et al.; Reddy et al., 2015; Patnaik et al.; Arun Kumar et al., 2017a; Jehangir et al.). In normal subjects or over the age of 60, EI is equal to or less than 0.29 (LeMay, 1984). The Evans ratio was found as 0.25 in Turkish females and males (Karakas et al.). The same dimension was 0.28 and 0.26 in Indian males and females (Patnaik et al.).

In South Indians, this value were between 0.27 and 0.26 both males and females (Arun Kumar et al., 2017a). However, Evans ratio was reported as 0.271 and 0.262 in Japan males and females, respectively (Takeda et al., 2003). The corresponding value was found as 0.260 in English population (Turner et al., 2001). In Singapore population, EI was found as 0.33 and 0.27 in subjects with idiopathic normal pressure hydrocephalus and healthy, respectively ( $\mathrm{Ng}$ et al.). In this study the same measurement was found as 0.28 and 0.27 females and males, respectively. Due to these reports, we found some differences between other populations and our values: especially South Indian, Japanese and Singapore people have lower values than us. In this investigation, the average total lengths of Evans Index were closer to the values given in ideal reference data (LeMay; Moore et al.; Kanakaraj et al.; Arun Kumar et al., 2017b).

From several studies about the mean of third ventricle width, they were reported to be $3 \mathrm{~mm}$ and $4 \mathrm{~mm}$ in females and males from Norway (ranged from $1.9 \mathrm{~mm}$ to $5.6 \mathrm{~mm}$ ); wheras, In England, the same dimension was determined as $5.14 \mathrm{~mm}$ (Turner et al.; Aukland et al.). Meanwhile the same measurement was found to be $6.39 \mathrm{~mm}$ and $5.09 \mathrm{~mm}$ in Japanese male and female people (Takeda et al.). It was found between $3.25 \mathrm{~mm}$ and $4.06 \mathrm{~mm}$ in Indian females and males (Kanakaraj et al.). In Turkish females and males the width value was reported as $3.79 \mathrm{~mm}$ and $4.12 \mathrm{~mm}$ (Karakas et al.). In Germany population, the same dimension was between $3.3 \mathrm{~mm}$ and $7.7 \mathrm{~mm}$ in age between 20 - 69 years old (Duffner et al.; Preul et al., 2006). In Goa population, this value was declared as $0.45 \mathrm{~cm}$ and $0.39 \mathrm{~cm}$ in males and females (D'Souza e Dias Medora \& Natekar Prashant, 2007). Gameraddin et al. declared this measurement as 5.70 $\mathrm{mm}$ and 5.40 in males and females. In this study, the mean mesurements were found as $3.37 \mathrm{~mm}$ and $3.91 \mathrm{~mm}$ in females 
and males, respectively. According to these data we found differences in average values of Japanese, United Kingdom, Germany, Goa population, Indians, Turkish, Englans, and our population. England, Japanese and Germany have higher values than ours. Moreover, as similarly to literature, the total averages of third ventricle width are higher in males than females. We think that these differences may be a result of some factors such as race, genetic variables, age, and sex.

The fourth ventricle width was found to be $13.0 \mathrm{~mm}$ and $12.0 \mathrm{~mm}$ in males and females, respectively (Honnegowda et al.). In Saudi Arabian males and females, the corresponding value was $12.54 \mathrm{~mm}$ and $11.60 \mathrm{~mm}$ (Gameraddin et al.). In Germany healthy population, the corresponding value was $12.5 \mathrm{~mm}$ (Duffner et al.). In Goa population, the same dimension was reported as $1.31 \mathrm{~cm}$ and $1.21 \mathrm{~cm}$ in males and females (D'Souza e Dias Medora $\&$ Natekar Prashant). In England population the same value was $0.92 \mathrm{~cm}$ (Turner et al.). In Indians, the same measurement was found as $12.16 \mathrm{~mm}$ and, $11.38 \mathrm{~mm}$ in males and females, respectively (Kanakaraj et al.). This value was higher in males than females and the highest the fourth ventricle values were in age group of $70 \mathrm{yrs}$ in both genders (Honnegowda et al.; Kanakaraj et al.).

As a conclusion, the observations presented in this study have defined anatomic parameters that need to be taken into consideration for evaluate ventricular size about brain volume changes and guidelines for determine the reference values in terms of Turkish population. Also, this paper can provide crucial information and may be essential for safe and accurate diagnose of many neurological disorders to evaluate both normal and pathological changes for surgeon, radiologist or neuroscientist about assessment of pathologic changes in the ventriculer region using with MRI. Moreover, these kinds of studies including age and gender are getting more and more important day by day. The obtained data can be used as the reference values in evaluating the brain region. Furthermore, we think that the normal reference values of ventricles obtained MRI are necessary baseline data for interpreting pathological changes, planning surgery, and determining presence and progress of some neurological diseases.

POLAT, S.; ÖKSÜZLER, F. Y.; ÖKSÜZLER, M.; KABAKCI, A. G. \& YÜCEL, A. H. Estudio morfométrico de resonancia magnética de los ventrículos cerebrales en sujetos turcos sanos. Int. J. Morphol., 37(2):554-560, 2018.

RESUMEN: El objetivo de este estudio fue determinar los valores normales de los ventrículos e índices cerebrales en sujetos sanos en nuestra población mediante el uso de imágenes de resonancia magnética $(\mathrm{RM})$ y revelar las diferencias relacionadas con el sexo y la edad. Se examinó la resonancia magnética de 265 individuos sanos de entre 18 y 87 años, y se utilizaron las imágenes en sentido medio y sagital para las mediciones. Las mediciones se realizaron a partir de IRM en una estación de trabajo. Se observaron los siguientes valores medios de ventrículos e índices cerebrales: longitud del asta frontal (FHW) $(33,14 \mathrm{~mm})$; longitud del tercer ventrículo (TVW) $(3,37 \mathrm{~mm})$; longitud anteroposterior del cuarto ventrículo (FVWAP) $(9,93 \mathrm{~mm})$; longitud transversal del cuarto ventrículo (FVWT) $(12,40 \mathrm{~mm})$; y el diámetro transversal máximo del cráneo (SID) $(128,75 \mathrm{~mm})$ en las hembras. Las mismas dimensiones fueron $34,85 \mathrm{~mm}, 3,91 \mathrm{~mm}, 10,26 \mathrm{~mm}, 12,81$ $\mathrm{mm}$ y $134,68 \mathrm{~mm}$ en machos, respectivamente. Hubo diferencias estadísticamente significativas en el ancho del asta frontal, el ancho del tercer ventrículo y el diámetro interno transversal máximo de los valores del cráneo entre los sexos. Los valores medios del índice de Evans que obtuvieron el ancho máximo entre los cuernos frontales de los ventrículos laterales dividido por el diámetro interno transversal máximo del cráneo se encontraron en 0,280 \pm 0,172 en las mujeres; mientras que las mismas dimensiones se calcularon en hombres $(0,276 \pm 0,161)$. Sin embargo, estos valores fueron más bajos en hombres sanos que en mujeres; no se encontraron diferencias significativas entre los grupos. Los hallazgos actuales obtenidos de IRM son datos anatómicos de referencia necesarios para interpretar los cambios patológicos, planificar la cirugía y determinar la presencia y el progreso de algunas enfermedades neurológicas.

PALABRAS CLAVE: Ventrículos cerebrales; Estudio Morfométrico; RM.

\section{REFERENCES}

Arun Kumar, S.; Kumari, S. M.; Anand, M. V.; Saraswathy, R. \& Rajeshwari, M. Evaluation of Evan's index in South Indian population using computed tomography. Int. J. Anat. Radiol. Surg., 6(3):RO28-31, 2017a.

Arun Kumar, S.; Kumari. S. M.; Pavithra, A. \& Saraswathy, R. CT Based study of frontal horn ratio and ventricular index in South Indian population. IOSR J. Dent. Med. Sci., 16(7):55-9, $2017 \mathrm{~b}$.

Aukland, S. M.; Odberg, M. D.; Gunny, R.; Chong, W. K.; Eide, G. E. \& Rosendahl, K. Assessing ventricular size: is subjective evaluation accurate enough? New MRI-based normative standards for 19-yearolds. Neuroradiology, 50(12):1005-11, 2008.

D'Souza e Dias Medora, C. \& Natekar Prashant, E. Morphometric study of the ventricular system of brain by computerised tomography. J. Anat. Soc. India, 56(1):19-24, 2007.

Duffner, F.; Schiffbauer, H.; Glemser, D.; Skalej, M. \& Freudenstein, D. Anatomy of the cerebral ventricular system for endoscopic neurosurgery: a magnetic resonance study. Acta Neurochir. (Wien), 145(5):359-68, 2003.

Farheen, S. S. \& Sukre, S. B. Morphometric study of frontal horn of lateral ventricle by computerised tomography. Int. J. Anat. Res., 5(3.1):40636, 2017.

Gameraddin, M.; Alsayed, A.; Ali, A. \& Al-Raddadi, M. Morphometric analysis of the brain ventricles in normal subjects using computerized tomography. Open J. Radiol., 5(1):13-9, 2015.

Honnegowda, T. M.; Nautiyal, A. \& Deepanjan, M. A Morphometric study of ventricular system of human brain by computerised tomography in an Indian population and its clinical significance. Austin J. Anat., 4(4):id1075, 2017. 
Jamous, M.; Sood, S.; Kumar, R. \& Ham, S. Frontal and occipital horn width ratio for the evaluation of small and asymmetrical ventricles. Pediatr. Neurosurg., 39(1):17-21, 2003.

Jehangir, M.; Dar, I. H.; Sahota, A.; Hassan, G. H.; Mustafa, K. \& Javaid, A. Normative parameters of Evans index using computerized tomographic scan in individuals of Kashmiri ethnicity. Int. J. Contemp. Med. Res., 5(6):F1-3, 2018.

Kanakaraj, K.; Kalaichezhian, M. \& Sunil, K. Morphometric study of the normal third and fourth ventricular sizes on computed tomography. SAS J. Med., 2(6):152-6, 2016.

Karakas, P.; Koç, F.; Koç, Z. \& Gülhal Bozkır, M. Morphometric MRI evaluation of corpus callosum and ventricles in normal adults. Neurol. Res., 33(10):1044-9, 2011.

Kulkarni, A.V.; Drake, J. M.; Armstrong, D. C. \& Dirsk, P. B. Measurement of ventricular size: reliability of the frontal and occipital horn ratio compared to subjective assessment. Pediatr. Neurosurg., 31(2):65-70, 1999.

LeMay, M. Radiologic changes of the aging brain and skull. AJR Am. J. Roentgenol., 143(2):383-9, 1984.

Liu, C.; Edwards, S.; Gong, Q.; Roberts, N. \& Blumhardt, L. D. Three dimensional MRI estimates of brain and spinal cord atrophy in multiple sclerosis. J. Neurol. Neurosurg. Pyschiatry, 66(3):323-30, 1999.

Mavridis, I. Clinical anatomy of the fourth ventricle foramina. OA Anat., 2(1):9, 2014.

Moore, D. W.; Kovanlikaya, I.; Heier, L. A.; Raj, A.; Huang, C.; Chu, K. W. \& Relkin, N. R. A pilot study of quantitative MRI measurements of ventricular volume and cortical atrophy for the differential diagnosis of normal pressure hydrocephalus. Neurol. Res. Int., 2012:718150, 2012.

Ng, S. E.; Low, A. M.; Tang, K. K.; Chan, Y. H. \& Kwok, R. K. Value of quantitative MRI biomarkers (Evans' index, aqueductal flow rate, and apparent diffusion coefficient) in idiopathic normal pressure hydrocephalus. J. Magn. Reson. Imaging, 30(4):708-15, 2009.

Patnaik, P.; Singh, V.; Singh, D. \& Singh, S. Age and gender related variations in lateral ventricle brain ratios. Int. J. Health Sci. Res., 6(5):7884, 2016.

Preul, C.; Hund-Georgiadis, M.; Forstmann, B. U. \& Lohmann, G. Characterization of cortical thickness and ventricular width in normal aging: a morphometric study at 3 Tesla. J. Magn. Reson. Imaging, 24(3):513-9, 2006.

Reddy, V. U.; Hegde, K. V.; Agrawal, A.; Pathapati, R. M. \& Arumulla, M. Normative values for Evan's index on CT scan for apparently healthy individuals. J. Anat. Soc. India, 64:137-40, 2015.

Takeda, S.; Hirashima, Y.; Ikeda, H.; Yamamoto, H.; Sugino, M. \& Endo, $\mathrm{S}$. Determination of indices of the corpus callosum associated with normal aging in Japanese individuals. Neuroradiology, 45(8):513-8, 2003.

Turner, B.; Ramli, N.; Blumhardt, L. D. \& Jaspan, T. Ventricular enlargement in multiple sclerosis: a comparison of three-dimensional and linear MRI estimates. Neuroradiology, 43(8):608-14, 2001.

\section{Corresponding author: \\ DR. Sema Polat \\ Çukurova University \\ Faculty of Medicine \\ Department of Anatomy \\ Adana \\ TURKEY}

\section{E-mail: sezaoz@hotmail.com}

Received: 31-10-2018

Accepted: 25-01-2019 